\title{
A INAPTIDÃo DE CANDIDATOS À DOAÇÃo DE SANGUE RELACIONADA À SOROPOSITIVIDADE AO HIV1/2 NO BRASIL
}

$\begin{array}{lccccc}\text { THE } & \text { INABILITY } & \text { OF } & \text { CANDIDATES } & \text { FOR } & \text { BLOOD } \\ \text { DONATION RELATED } & \text { WITH A } & \text { SEROPOSITIVITY HIV } & \text { I/2 IN BRAZIL }\end{array}$

\section{Milce Costa}

Doutora em Medicina Tropical. Docente da Faculdade de Ceres, Ceres - GO, Brasil. milcebiomol@yahoo.com.br

\section{Anapaula Gonçalves de Souza Portes}

Curso de Enfermagem. Facer - Faculdade de Ceres, Ceres - GO, Brasil. anapaula_portes@hotmail.com

\section{Raiane Antunes Sampaio}

Curso de Enfermagem. Facer - Faculdade de Ceres, Ceres - GO, Brasil. raianeantunes@ hotmail.com

RESUMO: O HIV (Human Immunodeficiency Virus) é transmitido primordialmente pela via sexual, no entanto, a transmissão por transfusão sanguínea tem se tornado uma grande preocupação para os serviços de hemoterapia. No caso dos bancos de sangue, uma das formas de evitar a transmissão consiste em um minucioso controle de qualidade do sangue doado. A triagem em bancos de sangue é dividida em duas etapas para um melhor rastreamento de infecções e melhora na qualidade do hemocomponente a ser transfundido. A primeira etapa é composta pela triagem clínica que consiste em uma anamnese do doador, analisando sua história clínica e as correlacionando aos seus comportamentos. A segunda etapa é a triagem sorológica que é uma forma fundamental de evitar a transmissão de vários agentes infecciosos como o HIV. Este trabalho trata-se de uma revisão bibliográfica relacionada a inaptidão de candidatos à doação de sangue com soropositividade para HIV1/2, realizado através de consulta em base de dados na biblioteca virtual de saúde (BVS), CAPES, SciELO, BIREME e PubMed. Este estudo teve como objetivo analisar a prevalência de doadores inaptos para HIV 1/2 nas cinco regiões do Brasil entre 2003 e 2013. Os resultados deste estudo mostraram que a maior prevalência de doadores inaptos com HIV foi encontrada em Belém - PA (Região 
Norte), a menor prevalência, no entanto, foi observada em Ribeirão Preto - SP (Região Sudeste), com percentuais de $10,14 \%$ e de $0,02 \%$ respectivamente. Portanto, um dos grandes desafios dos serviços de hemoterapia é a garantia do atendimento da demanda transfusional, bem como a qualidade e a segurança dos produtos sanguíneos.

Palavras-chave: HIV. Banco de sangue. Doador inapto.

ABSTRACT: HIV (Human Immunodeficiency Virus) is transmitted primarily through sexual contact, however, transmission by blood transfusion has become a major concern for hemotherapy services. In the case of blood banks, one way to avoid transmission consists of a thorough quality control of donated blood. The screening in blood banks is divided into two steps for better infections tracking and improves the blood quality components to be transfused. The first step consists in a clinical trial and a donor medical history, reviewing your medical history and correlating their behavior. The second step is serological screening which is a key way to prevent various infectious agents transmission such as HIV. This work is in a literature review related to disability of candidates for blood donation with seropositivity for HIV1/2, obtained through consultation database in virtual health library (VHL), CAPES, SciELO, PubMed and BIREME. This study aimed analyze the prevalence of unsuitable donors for HIV $1 / 2$ in the five regions of Brazil, between 2003 and 2013. The results of this study showed that the highest prevalence of unsuitable donors with HIV was found in Belém - PA (Northern Region), the lowest prevalence, however, was observed in Ribeirão Preto - SP (Southeast Region), with percentages of 10,14\% and 0,02\% respectively. Therefore, the major challenge for the transfusion service is the transfusional service demand guarantee as well as the quality and safety of blood products.

Keywords: HIV. Blood Bank. Unfit donor.

Endereço para correspondência: Milce Costa, Av. Brasil, S/N, Qd. 13 Morada Verde Ceres - Go, Fone: (62) 3323-1040, E-mail: milcebiomol@ yahoo.com.br 


\section{INTRODUÇÃO}

\section{BREVE HISTÓRICO}

Os primeiros casos de infecção pelo HIV/VIH (Human Immunodeficiency Virus/Vírus da Imunodeficiência Humana) ocorreram no ano de 1977 e 1978, nos EUA, Haiti e África Central. Já no Brasil, o primeiro caso ocorreu em 1982, mesmo ano em que a doença foi classificada como uma síndrome e nomeada temporariamente como doença dos "5 $\mathrm{H}$ ", homossexuais, haitianos, hemofílicos, heroinômanos (usuários de heroína injetável) e hookers (profissionais do sexo) (BRASIL, [s/d] ).

O HIV-1 foi isolado pela primeira vez em 1984 pelo pesquisador francês Luc Montaigner. Neste mesmo ano o americano Robert Gallo também disputava a primazia da descoberta do HIV, gerando um grande embate na comunidade científica (BRASIL, 2006a).

Existem dois tipos de HIV diferenciando-se apenas por modificações genéticas, o HIV-1, descoberto em 1984, encontrado em todos os continentes, e o HIV-2, descoberto em 1986, com prevalência restrita à África. No Brasil, predomina-se o HIV-1, sendo pouco frequentes as infecções pelo HIV-2 (FERREIRA, 2007).

Os primeiros casos de AIDS/SIDA (Acquired Immunodeficiency Syndrome/ Sindrome da Imunodeficiência Adquirida) confirmados no Brasil ocorreram no estado de São Paulo, e desde o início da década de 1980 até 2006, existiam mais de 600 mil brasileiros com o vírus da AIDS, sendo que mais de $80 \%$ concentravam-se nas regiões Sul e Sudeste. Colaborando com essa ideia as regiões Sul e Sudeste são as regiões mais acometidas desde o início da epidemia no país (BRASIL, 2006b).

\section{AGENTE ETIOLÓGICO}

O HIV faz parte da família Retroviridae, do gênero Lentivirus (ICTV, 2007). A família Retroviridae é caracterizada pela capacidade dos seus membros transcreverem o seu genoma de RNA para DNA antes de se integrarem ao cromossomo da célula hospedeira (LEWIS; EMERMAN, 1994).

Os retrovírus contêm três domínios codificantes: gag, que gera o capsideo viral; pol, que contém informações para as enzimas transcriptase reversa, integrase e protease, e env, que codifica as proteínas do envelope (LEWIS; EMERMAN, 1994). A transcriptase reversa é uma 
enzima chave do ciclo de replicação dos retrovírus, possuindo atividades de DNA polimerase dependente e RNA e RNase H (ISEL et al., 1999).

O HIV-1 é um vírus esférico com simetria icosaédrica, é formado por um envelope onde estão inseridas espículas que consistem de duas glicoproteínas, a gp120 (superfície) e a gp41 (transmembrana), as mesmas estão ligadas de maneira não covalente. Abaixo do envelope lipídico está uma estrutura composta de 2.000 cópias da proteína p17 que também é conhecida como proteína da matriz e essa proteína é que reveste a superfície interna do envelope viral (TURNER; SUMMERS, 1999).

O capsídeo viral é formado pela proteína p24 e está localizado no centro do vírus. Esse capsídeo envolve as duas cópias do genoma de RNA de fita simples e de polaridade positiva, o qual é estabilizado como um complexo de nucleoproteína com a proteína do nucleocapsídeo (p7) e também contém três enzimas virais essenciais: protease, transcriptase reversa e integrase. A maioria das funções conhecidas da proteína do nucleocapsídeo do HIV envolve interações com ácido nucléico (TURNER; SUMMERS, 1999).

\section{VIAS DE TRASMISSÃO}

Quanto às vias de transmissão do HIV relata-se a ocorrência através da relação sexual sem proteção principalmente em indivíduos sexualmente ativos que adotam comportamento de risco (promiscuidade), contato com sangue contaminado no caso de hemofílicos, usuários de drogas injetáveis e aqueles contaminados por transfusão sanguínea; de forma vertical durante o parto e pelo aleitamento materno (QUEIROZ et al., 2012).

A principal forma de transmissão em todo mundo ainda é a sexual. A propagação da infecção pelo HIV no Brasil vem, ao longo do tempo, sofrendo transformações significativas em seu perfil epidemiológico. O que antes era uma epidemia restrita a metrópoles nacionais, e marcadas por prevalência no sexo masculino em homossexual e indivíduos hemofílicos, hoje, encontra-se marcado pela prevalência em heterossexuais, atingindo por igual o sexo feminino (BRITO; CASTILHO; SZWARCWALD, 2000). A disseminação do HIV pelo uso de drogas injetáveis pode ser verificada através do compartilhamento de seringas e agulhas (BRASIL, 2004b). Já a transmissão vertical do HIV se faz possível pela exposição da criança na gestação (menos frequente no primeiro trimestre), parto ou no aleitamento materno (BRASIL, 2004c)

Na década de 1980, cerca de 70\% dos pacientes com hemofilia na Europa Ocidental e nos Estados Unidos foram infectados com o HIV, adquirido de concentrados plasmáticos 
(MANNUCCI; TUDDENHAM, 2001). O primeiro caso de HIV transmitido por meio de transfusão sanguínea ocorreu em 1981. O risco de se contrair o HIV por meio de transfusão sanguínea no final da década de 1980 era de 2 a 5\% (TORRES, 1988; HAMERSCHLAK, PASTERNAK, 1991).

Apesar de todos os avanços alcançados no combate à AIDS nas últimas décadas, ainda pode se considerar a transmissão do HIV por meio de transfusão sanguínea um problema mundial, sendo que esta incidência no Brasil apresenta-se 10 vezes maior que nos Estados Unidos e Europa (BARRETO et al., 2005). Em 2004 foram notificados no Brasil, 23 casos de HIV transfusional, contudo, a transmissão do HIV por transfusões sanguíneas ainda permanece incerta, tendo como base a ausência do conhecimento da situação sorológica do receptor antes da transfusão (BRASIL, 2004d).

\section{MANIFESTAÇÕES CLÍNICAS}

Os portadores do vírus HIV não tratados apresentam inicialmente sintomas inespecíficos como febre, linfadenopatia, faringite, fadiga e sudorese noturna e com a evolução da doença resulta em imunodeficiência com consequências fatais (ROBINSON, 1997).

As manifestações clínicas do HIV são divididas em três etapas, sendo a primeira infecção aguda, que ocorre de 0 a 12 semanas, caracteriza-se por manifestações de doenças transitórias sintomáticas, associada a uma constante replicação viral e a uma resposta imunológica específica. A segunda etapa intitula-se por fase assintomática ou de Latência clínica (de 1 a 5 anos). Esse período de latência do vírus é caracterizado pela ausência de sintomas e pela interação entre o sistema de defesa e as constantes mutações do vírus, mas não debilita o organismo causando outras doenças. Por fim a terceira etapa é definida como Síndrome da Imunodeficiência Adquirida $\left(\mathrm{CD} 4<350\right.$ células por $\mathrm{mm}^{3}$ ). Esta fase é caracterizada pela manifestação de doenças secundárias após a degradação imunológica. $\mathrm{O}$ paciente pode apresentar infecções por agentes oportunistas, doenças neoplásicas e quadros clínicos causados pela infecção crônica pelo próprio HIV (BRASIL, 2012b).

A Tabela 1 apresenta as principais doenças oportunistas causadas por vírus e fungos em pacientes HIV positivos. São descritas também as principais doenças causadas por bactérias, os tumores mais comuns e as dermatoses. 
Tabela 1. Principais doenças oportunistas causadas em pacientes HIV positivos.

\begin{tabular}{l}
\hline AGENTE ETIOLÓGICO/ DOENÇAS \\
MANIFESTAÇÕES
\end{tabular}

VÍRUS

Exantema Agudo (HIV)

Herpes Simples Tipo 1 e 2

Varícola Zóster

Leucoplasia Pilosa Oral

Papiloma Vírus Humano (HPV)

Molusco Contagioso

Citomegalovirus (CMV)

Candidíase

FUNGOS

Infecção por Dermatófitos

Pityrosporum Ovale

Micoses Profundas

BACTÉRIA

Sífilis

Angiomatose Bacilar

Micobactérias

TUMORES

Sarcoma de Kaposi

Neoplasias Cutâneas Primárias

Malignidades linforreticulares

DERMATOSES ERITÊMATO-

Dermatite Seborreica

DESCAMATIVAS

Psoríase

Dermatite Atópica

Xerodermia

Farmacodermias

Erupções Papulopruriginosas

Fonte: ROBINSON, P.G. The oral manifestations of HIV infection. Int. J. STD AIDS, vol. 8, p.668-74, 1997. 


\section{TRATAMENTO}

O tratamento antirretroviral para o HIV foi introduzido em 1996 através de uma combinação de pelo menos três drogas antirretrovirais (Tabela 2) conhecidos popularmente como "coquetel". O tratamento antirretroviral (TARV) tem por finalidade diminuir a mortalidade e as morbidades consequentes à infecção pelo HIV. Seu mecanismo inibe a replicação viral e leva à preservação da função imune e, com isso, à diminuição da frequência de infecções e neoplasias oportunistas. Contudo, essa medicação não proporciona a cura para os pacientes. É importante salientar que a adesão dos indivíduos ao tratamento não é fácil devido a alta toxicidade das drogas e ao grande número de comprimidos a serem ingeridos (OMS, 2004; BRASIL, 2012c).

O tratamento com antirretrovirais está dividido em cinco classes e possuem no total de 18 medicações (Tabela 2).

Tabela 2. Tratamento antiretrovirais (TARV)

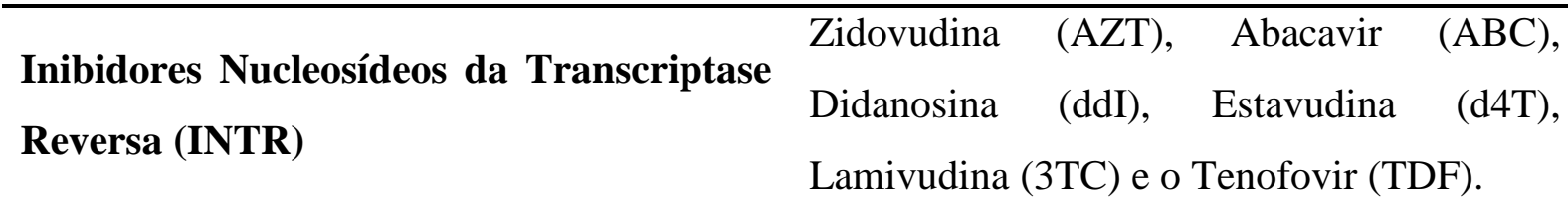
Inibidores Não Nucleosídeos da Efavirenz (EFV), Nevirapina (NVP) e a Transcriptase Reversa (INNTR) Etravirina (ETV).

Inibidores de Protease (IP)

Fosamprenavir (FPV), Atazanavir (ATV), Darunavir (DRV), Indinavir (IDV), Lopinavir/r (LPV/r), Nelfinavir (NFV), Ritonavir (RTV) e o Saquinavir (SQV).

Inibidores de Fusão (IF)

Enfuvirtida (T20)

Fonte: BRASIL. Recomendações para a prática de atividades físicas para pessoas vivendo com HIV e AIDS. Ministério da Saúde, Secretaria de Vigilância em Saúde, Departamento de DST, AIDS e Hepatites Virais. Brasília, 2012. 


\section{TRIAGEM CLÍNICA E LABORATORIAL}

Uma vez que as vias de transmissão do HIV são bastante conhecidas, prioriza-se orientar as formas de prevenção da doença. No caso dos bancos de sangue, uma das formas de evitar a transmissão consiste em um minucioso controle de qualidade do sangue doado (GONÇALVES et al., 2006).

Até a década de 1980, a doação de sangue no Brasil era feita de forma privada, sendo até remunerada. Após a descoberta do vírus HIV passou a ser um ato altruísta melhor regulamentado e também fiscalizado (LIMA, 2011). A partir de 1985 foi realizado o primeiro teste sorológico no Brasil para detecção do anticorpo anti-HIV na triagem sorológica de doadores de sangue. A detecção laboratorial é feita por meio de testes que pesquisem anticorpos, antígenos ou que isolem o vírus (SHARON, 2000). Atualmente exige-se a realização de exames de triagem sorológica em candidatos à doação de sangue em todos os serviços hemoterápicos brasileiros (BRASIL, 2010).

A triagem em bancos de sangue é dividida em duas etapas para um melhor rastreamento de infecções e melhora na qualidade do hemocomponente a ser transfundido. A primeira etapa é composta pela triagem clínica que consiste em uma anamnese do doador, analisando sua história clínica e as correlacionando aos seus comportamentos. A segunda etapa é a triagem sorológica que é uma excepcional forma de evitar a transmissão de vários agentes infecciosos como o HIV (PADILHA; WITT, 2011).

Os exames laboratoriais realizados em bancos de sangue preconizados pelo Ministério da Saúde, através da Lei $\mathrm{n}^{\circ}$ 7.649, em 1988 determinou que fossem realizados testes sorológicos para HIV1 e HIV2, Hepatite C, Hepatite B, vírus linfotrópico para células T humanas tipo I e II, Trypanosoma cruzi, Treponema pallidum, Plasmodium spp (SANTOS, MARCELLINI, RIBEIRO, 2008; GARCIA, SOUZA, 2009; RAMOS, FERRAZ, 2010).

Segundo o Ministério da Saúde o ideal é que se realizem dois testes, que devem ter princípios e/ou antígenos distintos. Ao menos um dos testes deve ser capaz de detectar anticorpos anti-HIV-1 e anti-HIV-2. Das amostras reagentes para os testes 1 e 2 deverão ser submetidas ao teste Western Blot, imunofluorescência indireta, ou PCR como caráter confirmatório. Por questão de segurança, se em um dos testes indicar anticorpos anti-HIV (sorologia positiva na triagem), já se faz suficiente para que a bolsa de sangue seja descartada (PEREIRA; NASCIMENTO, 2004).

Dessa forma, os testes mais utilizados são os que pesquisam anticorpos (sorológicos) devido à facilidade de realização, elevada especificidade e sensibilidade. O teste ELISA 
(Enzyme Linked Immunosorbent Assay) é utilizado preferencialmente para triagens de doadores de sangue por apresentar um baixo custo, sensibilidade e especificidade que ultrapassam 98\% (FERREIRA; ÁVILA, 2001).

Embora estes exames laboratoriais para HIV sejam sensíveis, ainda existe um período de janela imunológica (período que varia de 2 a 3 semanas a 6 meses) que se apresenta no início da infecção, podendo ocasionar resultados falsos negativos. A janela imunológica é o período de risco de disseminação do vírus HIV, ou seja, é o período que uma pessoa possui seus testes sorológicos negativos, porém, este indivíduo possui vírus suficientes para transmitir por meio de transfusão sanguínea (BRASIL, 2004a; FERNANDES, 2001).

Devido ao difícil diagnóstico para detecção do HIV no período de janela imunológica, fez-se necessária implementação de normas adicionais para a triagem sorológica nos bancos de sangue como a NAT (Nucleic Acid Test - NAT / Técnica de Detecção de Ácidos Nucléicos). O teste NAT foi desenvolvido para identificar vários tipos de RNA virais. Esta metodologia tem se tornado inevitável na triagem dos doadores de sangue. Com essa nova tecnologia alguns estudos evidenciaram a redução do período de janela imunológica de detecção do vírus HIV de 16-20 dias nos testes sorológicos para 10-12 dias através do teste NAT (VELATI et al., 2008; NUBLING, HEIDEN, CHUDY, 2009; ZOU et al., 2010).

A técnica NAT foi implantada na legislação brasileira pela a Portaria $n^{\circ}$ 262, de 2002 com o objetivo de diminuir o período de janela imunológica que identifica a infecção por HIV e HCV, aumentando assim a segurança transfusional (GARCIA; SOUZA, 2009). No entanto essa Portaria foi revogada devido à impossibilidade de instalação imediata desta técnica em todos os estados brasileiros em virtude das dificuldades de recolhimento de amostras, liberação de resultados, além do seu alto custo. Dessa forma foi indicada a inclusão gradativa deste teste no país (BRASIL, 2002).

Sendo assim, a presente pesquisa teve por objetivo analisar a prevalência de inaptidão em candidatos à doação de sangue com sorologia positiva para HIV 1/2 por regiões do Brasil entre 2003 a 2013 com o intuito de localizar os maiores índices de inaptidão para HIV 1/2.

\section{METODOLOGIA}

Trata-se de uma revisão bibliográfica, de aspecto quantitativo relacionado à inaptidão de candidatos à doação de sangue com soropositividade ao vírus HIV 1/2.

Este trabalho foi realizado através de consulta em base de dados na biblioteca virtual de saúde (BVS), CAPES, SciELO, BIREME e PubMed por meio de periódicos científicos, 
dissertações e teses referentes ao assunto abordado tendo como descritores: HIV, Banco de sangue, Doador inapto. Os textos foram analisados de forma completa, sendo selecionados os que correspondiam ao tema abordado.

O critério de inclusão utilizado correspondeu a artigos que abordavam o tema proposto, no período de 2003 a 2013, publicados no Brasil tanto em português quanto em inglês. Sendo excluídos os artigos que datam período inferior ao designado, e que não estiveram correspondendo ao tema proposto.

Foram utilizados para composição de tabela explicativa, 11 artigos científicos que nos possibilitavam realizar a seleção de estados das cinco regiões do Brasil que abordavam o tema proposto, onde os mesmos disponibilizavam a quantidade de doações realizadas bem como a prevalência de doadores inaptos com sorologia positiva para HIV por região (Nordeste, Sudeste, Centro-Oeste, Sul e Norte). 
Tabela 3. Prevalência de doadores inaptos com sorologia positiva para HIV 1/2 na triagem de serviços de hemoterapia no Brasil por regiões, no período de 2003 a 2013.

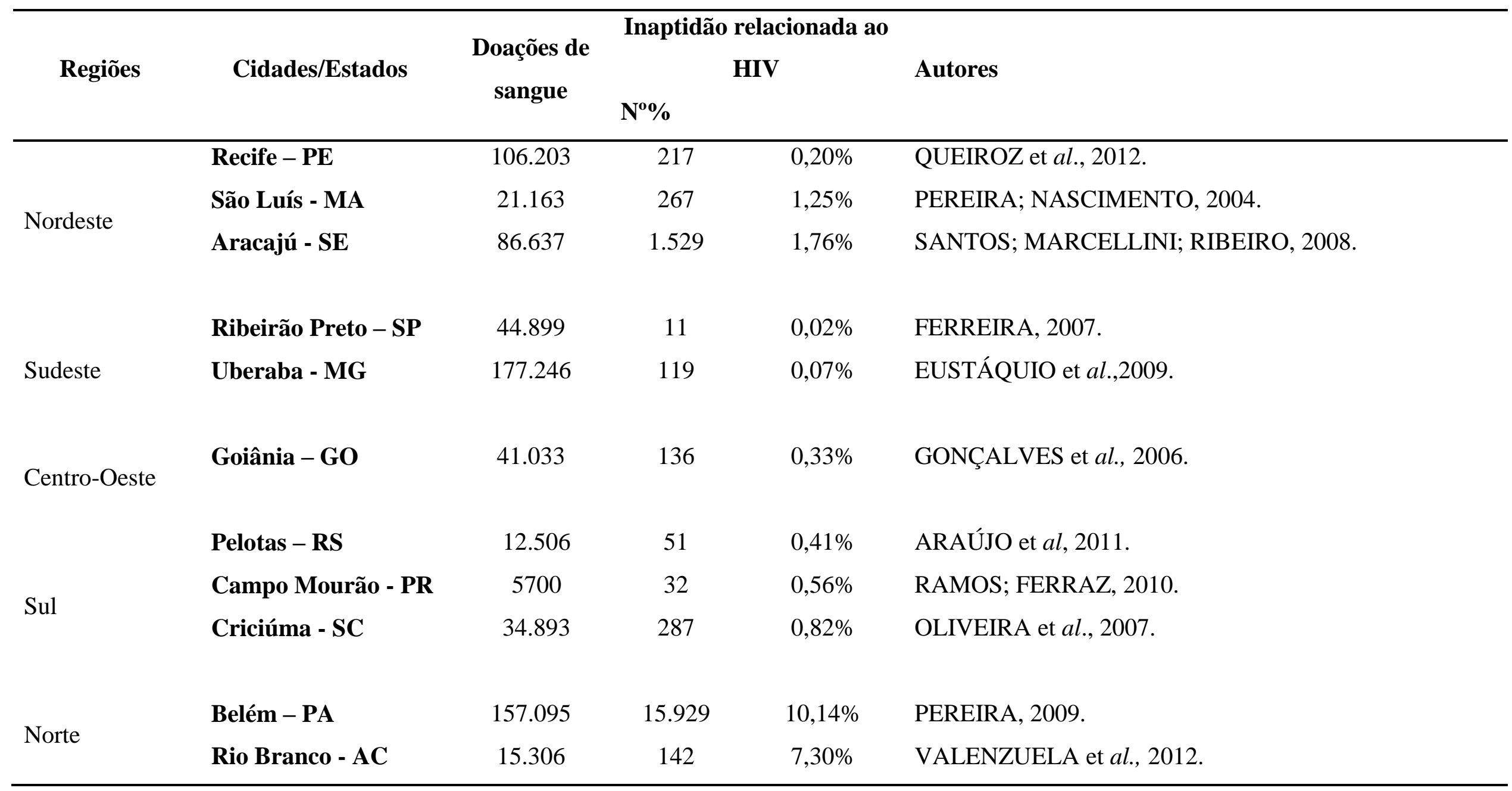




\section{RESULTADOS}

2

3

4

A Tabela 3 apresenta a distribuição de doadores inaptos à doação de sangue que apresentaram soropositividade para HIV 1/2, obtidos por análise bibliográfica de 11 artigos provenientes das cinco regiões do Brasil encontrados na literatura científica analisados no período compreendido entre 2003 a 2013.

Em relação aos valores máximos e mínimos de prevalência de candidatos inaptos com sorologia positiva para HIV 1/2, o levantamento realizado neste estudo mostrou que a maior prevalência foi encontrada em Belém - PA (região Norte), a menor prevalência, portanto, foi observada em Ribeirão Preto - SP (região Sudeste), com percentuais de 10,14\% e de 0,02\% de doadores inaptos com HIV respectivamente (FERREIRA, 2007; PEREIRA, 2009).

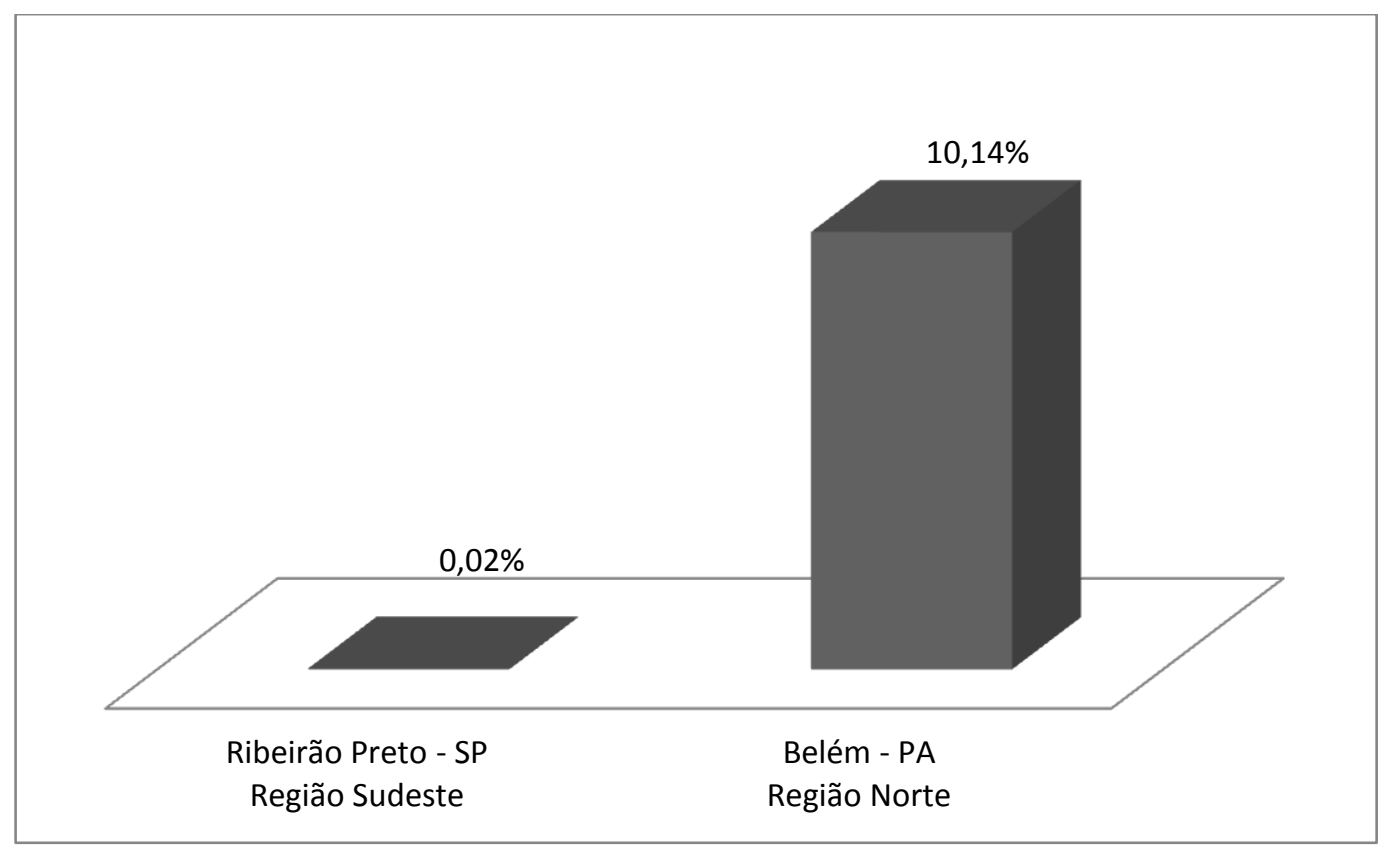

Figura 1 Menor e maior prevalência de sorologia positiva para HIV em candidatos à doação de sangue verificada nas 5 regiões pesquisadas.

Na região Nordeste foram encontrados três estudos correspondendo à prevalência de candidatos inaptos à doação de sangue nas cidades de Recife - PE, São Luís - MA e Aracajú SE, com percentuais de 0,20\%, 1,25\% e 1,76\% respectivamente (PEREIRA; NASCIMENTO, 2004; SANTOS, MARCELLINI, RIBEIRO, 2008; QUEIROZ et al., 2012), como mostra a Tabela 3.

Na região Sudeste foram visualizados as menores prevalências de doadores inaptos com sorologia positiva para HIV $1 / 2$ pesquisadas nas 5 regiões do país. As cidades de 
1 Ribeirão Preto - SP e Uberaba - MG (FERREIRA, 2007; EUSTÁQUIO et al., 2009) apresentaram prevalências de apenas $0,02 \%$ e $0,07 \%$, para este evento.

Em relação à região Centro-Oeste, a cidade de Goiânia - GO apresentou percentual de $0,33 \%$ de prevalência em relação aos doadores inaptos à doação de sangue que tiveram soropositividade para HIV 1/2 pesquisados (GONÇALVES et al., 2006).

No que diz respeito à região Sul, as cidades de Pelotas - RS, Campo Mourão - PR e Criciúma - SC apresentaram percentuais de 0,41\%, 0,56\% e 0,82\%, em relação aos candidatos à doação de sangue inaptos com sorologia positiva para HIV (ARAÚJO et al., 2011; RAMOS; FERRAZ, 2010; OLIVEIRA et al., 2007).

Das cidades e estados analisados na região Norte, Belém - PA e Rio Branco - AC (PEREIRA, 2009; VALENZUELA et al., 2012) apresentaram os maiores percentuais visualizados na pesquisa com $10,14 \%$ e $7,30 \%$, respectivamente.

\section{DISCUSSÃO}

A transmissão do HIV por meio de transfusão sanguínea representa um problema de saúde pública e um desafio para os serviços hemoterápicos em todo o mundo (BARRETO et al., 2005).

Os bancos de sangue no Brasil não apresentam informações suficientes sobre a ocorrência de sorologia positiva para o vírus HIV, no entanto, observa-se redução expressiva nos casos de transmissão do vírus HIV por via transfusional (BRASIL, 2007a). A redução dos casos pode ser explicada pelo fato da aplicação de determinados procedimentos como a triagem clínica bem conduzida, ensaios sorológicos mais sensíveis e pelo surgimento dos Centros de Testagem e Aconselhamento (CTAs) (SIQUEIRA, 2000; KUPEK, 2004).

No caso específico da triagem clínica do doador de sangue, é importante ressaltar que o indivíduo deve ser orientado e conscientizado a responder a entrevista com extrema veracidade, de modo a garantir uma maior segurança para os receptores do sangue doado (PEREIRA; NASCIMENTO, 2004). A entrevista da triagem clínica utiliza um roteiro padronizado que abrange questões referentes a gênero, idade, escolaridade, situação conjugal, tipo de doação, história de doença prévia ou atual, cirurgias e maior vulnerabilidade para DSTs (comportamento sexual) entre outras (BRASIL, 2007b; QUEIROZ et al., 2012).

Comprovadamente as triagens clínica e sorológica dos doadores nos bancos de sangue diminuem consideravelmente a probabilidade de transmissão do vírus HIV. No entanto, os ensaios para triagem sorológica não apresentam $100 \%$ de sensibilidade, principalmente na 
1 fase de janela imunológica (período que varia de 2 - 3 semanas, a 6 meses). Frente a essa

2 situação e buscando elevar a segurança transfusional, muitos serviços hemoterápicos utilizam

3 o NAT na triagem do HIV, por sua alta sensibilidade e por reduzir o período de janela 4 imunológica (FERNANDES, 2001).

5

A criação dos CTAs, unidades de saúde que atendem a demanda social proporcionando o acesso do indivíduo aos testes sorológicos (HIV, hepatite) gratuitamente e de forma anônima, reduziu consideravelmente o número de doadores inaptos nos bancos de sangue. Em regiões onde existe maior número de CTAs ativos verifica-se baixas prevalências de inaptidão sorológica nos bancos de sangue uma vez que o indivíduo pode utilizar-se do CTA para realizar testes como HIV sem a necessidade de recorrer ao banco de sangue com este intuito (SIQUEIRA, 2000; KUPEK, 2004; EUSTÁQUIO et al., 2009).

Em relação à investigação da prevalência de doadores inaptos com sorologia positiva para HIV 1/2 em serviços de hemoterapia no Brasil nas 5 regiões, há que se observar que a disseminação do HIV no país pode ser visualizada como uma epidemia com inúmeras características, uma vez que não possui um perfil epidemiológico único em todas as regiões, mas sim uma miscelânea de subepidemias originadas por diferenças socioeconômicas regionais (BRITO, 2000).

Ao avaliar comparativamente as regiões da Tabela 3 pode-se visualizar que as menores prevalências de doadores inaptos com sorologia positiva para HIV $1 / 2$ estão na região Sudeste com 0,02\% em Ribeirão Preto - SP e 0,07\% em Uberaba - MG (FERREIRA, 2007; EUSTÁQUIO et al., 2009).O encontro de baixas prevalências na região Sudeste pode der explicado inicialmente pelo grande número de CTAs ativas na região, bem como pela realização eficaz da triagem clínico-epidemiológica e das campanhas de fidelização de doadores vigente nos estados. Especificamente em Uberaba - MG verificou-se um declínio da ocorrência de doações com sorologia positiva para HIV depois da implantação do CTA neste município (BRASIL, 2008; EUSTÁQUIO et al., 2009).

Quanto à região Centro-oeste verificou-se escassez de trabalhos na literatura científica relacionados ao tema abordado, dessa forma sugere-se uma maior atenção para estudos relacionados à prevalência de doadores inaptos, principalmente nos estados do Mato Grosso MT e Mato Grosso do Sul - MS, o que colaboraria para o surgimento de novas linhas de pesquisa com base em dados de inaptidão para HIV.

Para analisar os maiores percentuais de doadores inaptos positivos para HIV descritos na região Norte neste estudo foi calculado uma média entre os percentuais de doadores inaptos soropositivos para HIV disponíveis através dos dados do Hemoprod (Relatório de 
1 Produção Hemoterápica) nos anos de 2010 e 2011. O Hemoprod é um boletim anual

2 disponível no Brasil com dados relacionados aos serviços de hemoterapia realizados no país.

3 Este boletim corresponde a um conjunto de planilhas contendo dados de produção enviados

4 pelos serviços de hemoterapia à Vigilância Sanitária local, no seu âmbito de atuação, e

5 posteriormente enviada para geração dos dados nacionais pela ANVISA. Este boletim consta

6 de apenas duas divulgações, uma de 2010, publicada em 2011 e outra de 2011, publicada em

7 2012. Dessa forma, a taxa percentual de inaptidão sorológica para o HIV no Brasil no ano de 82010 foi de 0,36\% e em 2011 foi de 0,33\% (BRASIL, 2012a). A média calculada e 9 estabelecida como parâmetro para esta análise foi de $0,34 \%$. Dessa forma podemos inferir que as prevalências de 10,14\% e 7,30\% referentes à região norte (Belém - PA e Rio Branco - AC) (PEREIRA, 2009; VALENZUELA et al., 2012) respectivamente são consideradas altas quando comparadas com a média nacional de inaptidão sorológica para HIV que é de $0,34 \%$. As altas prevalências de inaptidão sorológica para HIV observadas na região Norte provavelmente estão relacionadas a fatores comportamentais como atividade sexual de risco, escassez de CTAs na região e baixo nível de escolaridade (BRITO, CASTILHO, SZWARCWALD, 2000; ARAÚJO et al., 2005; BRASIL, 2008; GOVERNO DO ESTADO DO PARÁ, 2011).

\section{CONSIDERAÇÕES FINAIS} inaptos com sorologia positiva para HIV $1 / 2$ em serviços de hemoterapia nas diversas regiões do Brasil são de fundamental importância para verificar a situação transfusional dos bancos de sangue no país revelando o perfil de cada região especificamente. Neste contexto, torna-se imprescindível ressaltar que, para garantir segurança e qualidade no processo transfusional, todos os procedimentos realizados nos serviços de hemoterapia devem obrigatoriamente obedecer a rígidos padrões de qualidade, bem como a execução de cada etapa ser realizada por profissionais capacitados e utilizando técnicas específicas e adequadas. 


\section{REFERÊNCIAS}

ARAÚJO, B.A.; NECHTIGAL, G.C.; CERQUEIRA, M.S.P.; FERREIRA, A.P.S.; ALMEIDA, S.E.M.; SILVA, C.M.D. Prevalência de HIV em doadores de sangue do Sul do Rio Grande do Sul, Brasil. Rev. Panam. Infectol, vol. 13, nº 1, p. 19-22, 2011.

ARAÚJO, L.C.; FERNANDES, R.C.S.C.; COELHO, M.C.P.; ACOSTA, E.M. Prevalência da infecção pelo HIV na demanda atendida no Centro de Testagem e Aconselhamento da Cidade de Campos dos Goytacazes, Estado do Rio de Janeiro, Brasil, 2001-2002*. Epidemiologia e Serviços de Saúde, vol. 14, nº 2, p: 85-90, 2005.

BARRETO, C.C.; SABINO, E.C.; GONÇALEZ, T.T.; LAYCOCK, M.E.; PAPPALARDO, B.L.; SALlES, N.A, WRIGHT, D.J.; CHAMONE, D.F.; BUSCH, M.P. et al. Prevalence, incidence, and residual risk of human immunodeficiency virus among community and replacement first-time blood donors in São Paulo, Brazil. vol. $45 \mathrm{n}^{\circ}$ 11, p. 1709-14, 2005. Disponível em: < http://www.ncbi.nlm.nih.gov/pubmed/16271094> Acesso: 30 set. 2013.

BRASIL. ANVISA - Agência Nacional de Vigilância Sanitária. Boletim Anual de Produção Hemoterápica. Ano II nº 2, 2012a.

Boletim Epidemiológico: Aids/DST - Preliminar. Ano IX - $\mathrm{n}^{\circ} 01$ até semana epidemiológica $26^{\mathrm{a}}$. Brasília, 2012b.

Disponível em: <http://www.aids.gov.br/publicacao/2012/boletim-epidemiologico-aids-e-dst2012>. Acesso: 16 abr. 2013.

Recomendações para a prática de atividades físicas para pessoas vivendo com HIV e AIDS. Ministério da Saúde, Secretaria de Vigilância em Saúde, Departamento de DST, AIDS e Hepatites Virais. Brasília, 2012c.

ANVISA, Resolução RDC $n^{\circ}$ 57, de 16 de dezembro de 2010. Determina o Regulamento Sanitário para Serviços que desenvolvem atividades relacionadas ao ciclo produtivo do sangue humano e componentes e procedimentos transfusionais.

Ministério da Saúde. Secretaria de Vigilância em Saúde. Programa Nacional de DST e Aids. Contribuição dos centros de testagem e aconselhamento para universalizar o diagnóstico e garantir a equidade no acesso aos serviços. Brasília: Ministério da Saúde, n. 11, p. 108, 2008.

Ministério da Saúde. Boletim Epidemiológico AIDS. Ano IV n ${ }^{\circ} 1$ - julho a dezembro de 2006/ janeiro a junho de 2007a. 
ANVISA. Hemovigilância: manual técnico para investigação das reações transfusionais imediatas e tardias não infecciosas. Brasília: Anvisa, p. 124, 2007 b.

Ministério da Saúde. HIV/Aids, hepatites e outras DST / Ministério da Saúde, Secretaria de Atenção à Saúde, Departamento de Atenção Básica. - Brasília : Ministério da Saúde, 2006a.

Ministério da Saúde. Programa Nacional de DST e AIDS. Boletim epidemiológico AIDS. Brasília-DF, Ano III, nº 1, Jan a Jun/ 2006b.

Disponível em: <http://bvsms.saude.gov.br/bvs/periodicos/BOLETIM2006internet.pdf> Acesso: 16 out. 2013.

Ministério da Saúde. Secretaria de Vigilância em Saúde. Programa Nacional de DST e Aids. Implicações Éticas do Diagnóstico e da Triagem Sorológica do HIV / Secretaria Vigilância em Saúde, Programa Nacional de DST e Aids. - Brasília: Ministério da Saúde, 2004a.

Ministério da Saúde. Secretaria de Atenção à Saúde. SVS/CN - DST/AIDS. A Política do Ministério da Saúde para Atenção Integral a Usuários de Álcool e outras Drogas. 2.ed. rev. ampl.- Brasília: Ministério da Saúde, 2004b.

Ministério da Saúde. Coordenação Nacional de DST e Aids. Guia de tratamento clínico da infecção pelo HIV em crianças. Brasília: MS, 2004c.

Ministério da Saúde. Casos de aids (número e percentual) em indivíduos menores de 13 anos de idade, segundo categoria de exposição hierarquizada por ano de diagnóstico. Brasil, 1983-2004. Boletim-Epidemiológico - Aids e DST. vol.1 n ${ }^{\circ}$ 31, 2004d. Disponível em: <http://www.aids.gov.br/data/documents/storedDocuments/\%7BB8EF5DAF-23AE4891-AD36-1903553A3174\%7D/\%7B47CC4C73-91C6-4E44-A6703D92ADF2A59E\%7D/BOLETIM2.pdf.> Acesso: 23 abr. 2013.

. Ministério da Saúde. História da Aids. Departamento de DST, Aids e Hepatites Virais. Portal sobre aids, doenças sexualmente transmissíveis e hepatites virais. [s/d]. Disponível em: <http://www.aids.gov.br/pagina/historia-da-aids> Acesso: 14 abr. 2013.

. Portaria GM/MS n. ${ }^{\circ}$ 1407, de 01 de agosto de 2002. Revogação da Portaria 262, de $\mathbf{0 5}$ de fevereiro de 2002.

Disponível em: <http://www.saude.mg.gov.br/images/documentos/PORTARIA_1407.pdf> Acesso: 13 jun. 2013. 
BRITO, A. M; CASTILHO, E. A; SZWARCWALD, C. L. AIDS e infecção pelo HIV no Brasil: uma epidemia multifacetada. Revista da Sociedade Brasileira de Medicina Tropical. vol. 34, $n^{\circ} 2$, p. 207-217, 2000.

EUSTÁQUIO, J.M.J.; LIMA, G.M.; MARTINS, R.A.; SOUZA, H.M.; MARTINS, P.R.J.; Ocorrência de doações de sangue com sorologia positiva para o vírus HIV no Hemocentro Regional de Uberaba (MG) - fundação HEMOMINAS no período de 1995 a 2006. vol. 38, n 2, p. 73-81, 2009.

FERNANDES, M.F.A. Hemovigilância: análise das informações disponíveis para sua implementação, de acordo com a (re) investigação de casos de Aids associados à transfusão. Tese de Mestrado, Faculdade de Saúde Pública da Universidade de São Paulo, 2001.

FERREIRA, A.W.; ÁVILA, S.L.M. Diagnóstico laboratorial das principais doenças infecciosas e auto-imunes. 2. ed. São Paulo. Ed. Guanabara Koogan, 2001.

FERREIRA, O. Estudo de doadores de sangue com sorologia reagente para hepatites $\mathbf{B}$ e C, HIV e Sífilis no Hemocentro de Ribeirão Preto. (Dissertação de Mestrado) Universidade de São Paulo - Faculdade de Medicina de Ribeirão Preto/ Universidade de São Paulo, 2007.

GARCIA, F.B.; SOUZA, H.M. Não comparecimento de doadores inaptos sorológicos para repetição dos testes - O que fazer? (Carta ao Editor). Rev. Bras. Hematol. Hemoter, vol. 31, no 4, p. 291-292, 2009.

GONÇALVES, K.I; SOUZA, E.M; MODESTO, L.S; FONSECA, A.F; ALCÂNTARA, K.C. Soroprevalência de HIV-1/2 entre doadores de sangue de Goiânia-Goiás. RBAC, vol. 38, nº4, p. 263-266, 2006.

GOVERNO DO ESTADO DO PARÁ. SECRETARIA DE ESTADO DE PLANEJAMENTO, ORÇAMENTO E FINANÇAS INSTITUTO DE DESENVOLVIMENTO ECONÔMICO, SOCIAL E AMBIENTAL DO PARÁ. ESTATÍSTICA MUNICIPAL, 2011.

Disponível em: <http://iah.iec.pa.gov.br/iah/fulltext/georeferenciamento/belem.pdf>. Acesso: 15 out. 2013.

HAMERSCHLAK, N.; PASTERNAK, J. Doenças transmissíveis por transfusão. São Paulo: Organização Andrei, 1991.

KUPEK, E. Transfusion risk for Hepatitis B, Hepatitis C and HIV in the State of Santa Catarina, Brazil, 1991-2001. Braz J Infect Dis, nº 8, p. 236-240, 2004. 
ICTV - International Committee on Taxonomy of Viruses, 2007. Disponível em: <http://www.ncbi.nlm.nih.gov/ICTVdb/index.htm>. Acesso: 04 mar. 2013.

ISEL, C.; WESTHOF, E.; MASSIRE, C.; GRICE, S.F.J.L.E.; EHRESMANN, B.; EHRESMANN, C.; MARQUET, R. Structural bases for the especifty of the initiation of HIV 1 reverse transcription. The European Molecular Biology Organization Journal, vol. 18, no 4, p. 1038-1048, 1999.

LEWIS, P.F.; EMERMAN, M. Passage through mitoses is requires for oncoretroviruses but not for the human immunodeficiency virus. Journal of Virology, vol. 68, p. 510-516, 1994.

LIMA, D.S. Estudo comparativo de metodologias de triagem para HIV e HCV em doadores de sangue. Programa de pós-graduação em Hematologia lato sensu. Brasília - DF, 2011.

MANNUCCI, P.M.; TUDDENHAM, E.G.D. The Hemophilias - From Royal Genes to Gene Therapy. N. Engl. J. Med, vol. 344, nº 23, 2001.

NUBLING, C.M.; HEIDEN, M.; CHUDY, M. Experience of mandatory nucleic acid test (NAT) screening across all blood organizations in Germany: NAT yield versus breakthrough transmissions. Transfusion, vol. 49, p.1850-1858, 2009.

OLIVEIRA, L.H.C.; BALDESSAR, M.Z.; BOLAN, R.; SILVA, R.M. Prevalência de soropositividade em doadores de sangue no centro de hematologia e hemoterapia de Criciúma - SC, no período de 2002 a 2004. Arquivos Catarinenses de Medicina, vol. 36, nº 3, 2007.

PADILHA, D.Z;; WITT, R.R.I. Competências da enfermeira para a triagem clínica de doadores de sangue. Rev Bras Enferm, Brasília, vol. 64, n², p.234-40, 2011.

PEREIRA, A.M.B.; NASCIMENTO, F.R.F. Prevalência de HIV entre doadores de sangue no banco de sangue do Maranhão. DST - J bras Doenças Sex Transm, vol. 16, nº4, p.11-13, 2004.

PEREIRA, L.M.C.M. Perfil epidemiológico dos doadores de sangue da fundação HEMOPA em Belém-Pará, infectados pelo Vírus da Imunodeficiência Humana. 2009. 85 f. Dissertação (Biologia de Agentes Infecciosos e Parasitários) - Universidade Federal do Pará. Instituto de Ciências Biológicas. Belém. 
QUEIROZ, N.M.; SAMPAIO, D.A.; SANTOS, E.S.; BEZERRA, A.C. Modelo logístico na determinação de fatores associados à infecção HIV em doadores de sangue na Fundação HEMOPE. Rev. Bras. Hematol. Hemoter, vol. 34, nº 3, p. 217-21, 2012.

RAMOS, V.F.; FERRAZ, F.N. Perfil epidemiológico dos doadores de sangue do hemonúcleo de Campo Mourão-PR no ano de 2008. SaBios: Rev. Saúde e Biol., vol.5, n², p.14-21, 2010.

ROBINSON, P.G. The oral manifestations of HIV infection. Int. J. STD AIDS, vol. 8, p.66874, 1997.

SANTOS, E.A.; MARCELLINI, P.S.; RIBEIRO, J.P. Avaliação epidemiológica das rejeições dos doadores de sangue no HEMOLACEN/SE no período de 2004 a 2006. RBAC, vol. 40, nº , p. 251-256, 2008.

SIQUEIRA, E.M.P. Perfil de risco e avaliação do teste rápido para o vírus da Imunodeficiência Humana em voluntários do Centro de Testagem e Aconselhamento na cidade de Goiânia-Goiás, 2000. Dissertação (Mestrado). Universidade Federal de Goiás, Instituto de Patologia Tropical e Saúde Pública.

SHARON, J. Imunologia básica. Rio de Janeiro. Guanabara Koogan, 2000.

TORRES, A. Síndrome de Imunodeficiência Adquirida y transfusión. Rev. Med. Hosp. Univ. Nuestra Senõra de Assunción, vol. 2, nº 2, p. 34-37, 1988.

TURNER, B.G.; SUMMERS, M.F. Structural Biology of HIV. Journal of Molecular Biology, vol. 285, p.1-32, 1999.

VALENZUELA, E.V.; FERREIRA, E.R.; SILVA, K.R.; SOUZA, N.C.; DEFFUNE, E. Importância da Pré-Triagem Sorológica para Hepatite B em Doadores de Sangue no Estado do Acre. PARTE IV - SOROLOGIA.Ministério da Saúde. Segurança Transfusional: um olhar sobre os serviços de hemoterapia das regiões Norte e Centro Oeste do Brasil. III Curso de Especialização em Segurança Transfusional. Brasília, p. 354, 2012.

VELATI, C.; ROMANÒ, L.; FOMIATTI, L.; BARUFFI, L.; ZANETTI, R. Impact of nucleic acid testing for hepatitis $B$ vírus, hepatitis $C$ vírus and human immunodeficiency vírus on the safety of blood supply in Italy: a 6-year survey. Transfusion, vol. 48, p. 2205-2213, 2008. 
1 OMS. Organização Mundial da Saúde. TB/HIV MANUAL CLÍNICO. Departamento Stop

2 TB. Departamento de HIV/SIDA. Departamento de Saúde e Desenvolvimento da Criança e 3 do Adolescente. $2^{\text {a }}$ edição, p. 329, 2004.

4

5

6 ZOU, S.; DORSEY, K. A.; NOTARI, E. P.; FOSTER, G.A. et al. Prevalence, incidence 7 and residual risk of human immunodeficiency vírus and hepatitis $\mathrm{C}$ vírus infections amosng 8 United States blood donors since the introduction of nucleic acid testing. Transfusion, vol. 9 50, p. 1495-1504, 2010. 